\title{
Effect of Anisotropy Structure on Plume Entropy and Reactive Mixing in Helical Flows
}

\author{
Ye, Yu; Chiogna, Gabriele; Lu, Chunhui; Rolle, Massimo
}

Published in:

Transport in Porous Media

Link to article, DOI:

10.1007/s11242-017-0964-3

Publication date:

2018

Document Version

Peer reviewed version

Link back to DTU Orbit

Citation (APA):

Ye, Y., Chiogna, G., Lu, C., \& Rolle, M. (2018). Effect of Anisotropy Structure on Plume Entropy and Reactive Mixing in Helical Flows. Transport in Porous Media, 121(2), 315-332. https://doi.org/10.1007/s11242-017-0964-3

\section{General rights}

Copyright and moral rights for the publications made accessible in the public portal are retained by the authors and/or other copyright owners and it is a condition of accessing publications that users recognise and abide by the legal requirements associated with these rights.

- Users may download and print one copy of any publication from the public portal for the purpose of private study or research.

- You may not further distribute the material or use it for any profit-making activity or commercial gain

- You may freely distribute the URL identifying the publication in the public portal 
This is a Post Print of the article published on line $13^{\text {th }}$ November 2017 in Transport in Porous Media. The publishers' version is available at the permanent link: https://doi.org/10.1007/s11242-017-0964-3

\section{Effect of Anisotropy Structure on Plume Entropy and Reactive Mixing in} Helical Flows

4 
Plume dilution and reactive mixing can be considerably enhanced by helical flows occurring in three-dimensional anisotropic porous media. In this study, we perform conservative and reactive transport simulations considering different anisotropy structures of a single inclusion with the objective of exploring the effect of the inclusion's geometry and orientation on the patterns of twisted streamlines and on the overall dilution and reaction of solute plumes. We analyzed one hundred different scenarios by varying key parameters such as the angle of the anisotropic structures with respect to the average flow velocity, the spacing between alternated heterogeneous zones of coarse and fine materials, the permeability contrast between such matrices, and the magnitude of the seepage velocity. Entropy conservation equations and entropy-based metrics for both conservative and reactive species were adopted to quantify dilution, reactive mixing and their interactions with the helical flow patterns in the considered three-dimensional anisotropic setups. The results allowed identifying optimal anisotropic configurations maximizing mixing and reactions, and yielding enhancement factors up to 15 times the outcomes of analogous simulations in homogeneous media. Furthermore, the effects of compound-specific diffusive/dispersive properties of the transported species were found to be relevant for both plume dilution and reactive mixing in helical flows.

Keywords: anisotropy; helical flow; entropy; dilution; reactive mixing 


\section{Introduction}

The interplay between physical mixing processes and (bio)chemical reactions is of crucial importance for solute transport in natural flows, as well as in engineered systems (e.g., Stroock et al. 2002; Weiss and Provenzale 2008). Reaction kinetics are often rate-limiting in well mixed systems, such as in turbulent flows (e.g., Ottino 1989), whereas mixing controls chemical and biological reaction rates under poorly mixed conditions. The latter is typically the case for creeping flows and mixing-controlled reactive transport in porous media (e.g., Tartakovsky 2009; Willingham et al. 2008). A number of studies have investigated solute transport and mixing in porous media setups at different scales: from microfluidic experiments and pore-scale simulations (e.g., Acharya et al. 2007; Crevacore et al. 2016; de Anna et al. 2014; Hochstetler et al. 2013; Icardi et al. 2014; Jimenez-Martinez et al. 2015; Rolle et al. 2012;) to field-scale investigation and modeling studies of transport in aquifer systems (e.g., Amos et al. 2011; Cirpka et al. 2012; Liedl et al. 2005 and 2011; Prommer et al. 2009; Rolle et al. 2013a; Tuxen et al. 2006; Zarlenga et al. 2013).

The heterogeneity of porous formations has been recognized as the key feature for solute transport and mixing (e.g., Sanchez-Vila et al. 2006). For instance, the role of flow focusing in high-permeability inclusions and its effect on mixing and reactions in saturated porous media has been extensively studied in both two-dimensional and three-dimensional experimental and modeling setups (e.g., Bauer et al. 2009; Castro-Alcala et al. 2012; Cirpka et al. 2011; de Barros et al. 2015; de Dreuzy et al. 2012; Herrera et al. 2010; Fox et al. 2016; Muniruzzaman et al. 2014; Werth et al. 2006; Ye et al. 2015a). Compared to heterogeneity, the anisotropy of porous formations has received considerably less attention in the study of flow and transport (e.g., Di Dato et al. 2016a and 2016b; Pedretti et al. 2014; Ursino 2004; Zarlenga and Fiori 2015), particularly for the study of mixing and reactive processes. In modeling studies in three-dimensional anisotropic porous media, Hemker et al. (2004), Hemker and Bakker (2006) 
and Stauffer (2007) showed the existence of whirling streamlines which can considerably affect solute transport. The link between complex three-dimensional flow topology in heterogeneous anisotropic porous media and mixing has been addressed in a few recent modeling works (Bennet et al. 2017; Chiogna et al. 2014, 2015 and 2016; Cirpka et al. 2015). Also experimentally, only a limited number of studies have addressed the effects of anisotropy structures on flow and transport in porous media (e.g., Theis 1967; Ursino 2001; Ye et al. 2015b and 2016). The work of Ye et al. (2015b) provided first experimental evidence of helical flow in porous media: helical flow, entailing twisting streamlines, was obtained in a laboratory flow-through setup packed to obtain a spatially heterogeneous and anisotropic permeability. The outcomes of such experimental study motivate the model-based investigation of mixing enhancement in helical flows performed in the current investigation.

The objective of this work is to systematically analyze and assess the effects of anisotropy structures on dilution and reactive mixing enhancement in three-dimensional twisting flows in porous media. We consider a single macroscopic anisotropic inclusion, obtained with alternating slices of fine and coarse materials, embedded in a homogeneous porous matrix. We design twenty-five different configurations by changing the geometry (i.e., the orientation angle and the width of the alternating slices of low and high hydraulic conductivity) of the macroscopic anisotropic inclusion resulting in helical flows within the three-dimensional domain. Simulations of steady-state flow and transport were carried out with a recently proposed three-dimensional modeling approach to compute twisted flows in anisotropic media (Cirpka et al. 2015), which was validated with experimental data from high-resolution flow-through experiments (Ye et al. 2015b). The simulations were performed considering different seepage velocities, as well as different permeability contrasts between the fine and coarse porous media. Dilution and reactive mixing enhancement for conservative and mixing-controlled reactive transport are quantified by considering entropy balances and 
entropy-based metrics of mixing for both conservative and reactive species. For the reactive transport simulations in the different configurations of helical flow, we compute the critical dilution index (i.e., the amount of dilution necessary to completely degrade a mixing-controlled reactive plume) and we compare the results with the analytical expression for a three-dimensional homogeneous porous medium. Finally, we explore the effect of compound-specific diffusion in advection-dominated helical flows and its impact on mixing of conservative and reactive solute plumes.

\section{Flow and Transport Modeling}

\subsection{Governing equations}

The governing equation for steady-state flow in porous media is obtained by combining the continuity equation with Darcy's law:

$$
\nabla \cdot(\mathbf{q}(\mathbf{x}))=\nabla \cdot(-\mathbf{K}(\mathbf{x}) \nabla \phi(\mathbf{x}))=0
$$

where $\mathbf{q}\left[\mathrm{LT}^{-1}\right]$ is the specific discharge vector, $\mathbf{K}\left[\mathrm{LT}^{-1}\right]$ is the hydraulic conductivity tensor, $\mathbf{x}$ $[\mathrm{L}]$ is the vector of spatial coordinates, and $\phi[\mathrm{L}]$ is the hydraulic head.

The advection-dispersion equation describes solute transport in porous media. For steady-state reactive transport such equation reads as:

$$
\mathbf{v} \cdot \nabla c-\nabla \cdot(\mathbf{D} \nabla c)=r
$$

where $\mathbf{v}\left[\mathrm{LT}^{-1}\right]$ is the seepage velocity vector (i.e., $\left.\mathbf{v}=\mathbf{q} / \theta\right), \theta[-]$ is the porosity, $c\left[\mathrm{ML}^{-3}\right]$ is the concentration, $\mathbf{D}\left[\mathrm{L}^{2} \mathrm{~T}^{-1}\right]$ is the hydrodynamic dispersion tensor, and $r\left[\mathrm{ML}^{-3} \mathrm{~T}^{-1}\right]$ is the reaction rate which equals to zero for conservative solute transport. For steady-state transport of continuously emitted plumes, the transverse component of the dispersion tensor is of key importance (Cirpka et al. 2011). In this work we describe the transverse dispersion coefficient, $D_{t}\left[\mathrm{~L}^{2} \mathrm{~T}^{-1}\right]$, with the non-linear, compound-specific parameterization proposed by Chiogna et 
al. (2010) i.e., $D_{t}=D_{p}+D_{a q}\left(\frac{P e^{2}}{P e+2+4 \delta^{2}}\right)^{\beta}$, in which $D_{p}\left[\mathrm{~L}^{2} \mathrm{~T}^{-1}\right]$ is the pore diffusion coefficient, $P e=v d / D_{a q}[-]$ is the grain Péclet number, $v\left[\mathrm{LT}^{-1}\right]$ is the magnitude of the seepage

132 are zero. $X_{c r i t}$ is defined as $X_{c r i t}=\frac{f_{a} c_{B}^{a m b}}{f_{b} c_{B}^{a m b}+f_{a} c_{A}^{i n}}$, where $c_{B}^{a m b}\left[\mathrm{ML}^{-3}\right]$ is the concentration of velocity, $d[\mathrm{~L}]$ is the grain diameter, $D_{a q}\left[\mathrm{~L}^{2} \mathrm{~T}^{-1}\right]$ is the aqueous diffusion coefficient, $\delta[-]$ is the ratio between the length of a pore channel and its hydraulic radius, and $\beta[-]$ is an empirical exponent that accounts for the degree of incomplete mixing within the pore channels. Values of $\delta=5.37$ and $\beta=0.5$ were taken from the study of Ye et al. (2015c), which compiled experimental data on transverse dispersion from a number of two-dimensional and fully three-dimensional flow-through experiments in porous media with different grain sizes.

In the reactive transport scenarios, we considered a simple instantaneous bimolecular reaction (i.e., $f_{a} A+f_{b} B \rightarrow f_{c} C$ ), such that the reaction is completely mixing-controlled. Here $f_{a}, f_{b}$ and $f_{c}$ are the stoichiometric coefficients of the reaction, which were set to unity in this study. Species $A$ represents the plume of continuously emitted contaminant, whereas species $B$ is a reactant presented in the ambient water. Assuming the same diffusive properties for the two reactants, a virtual conservative compound $X[-]$, denoted as mixing ratio, can be used to describe the reactive transport problem (Cirpka and Valocchi 2007). $X$ represents the volumetric ratio of the source-related solution in the mixture with the ambient solution. The critical mixing ratio, $X_{\text {crit }}[-]$, is the value of $X$ at which the concentrations of both reactants species $B$ in the ambient water and $c_{A}^{i n}\left[\mathrm{ML}^{-3}\right]$ is the concentration of species $A$ at the inlet source. The concentrations of the different reactive species can be obtained from the distribution of the conservative mixing ratio. For instance, the concentration of reactant $A$ (i.e. $c_{A}$ ) and product $C$ (i.e. $c_{C}$ ), can be computed as: 


$$
\begin{gathered}
c_{A}= \begin{cases}X c_{A}^{i n}-\frac{f_{a}}{f_{b}}(1-X) c_{B}^{a m b} & X \geq X_{c r i t} \\
0 & X<X_{c r i t}\end{cases} \\
c_{C}= \begin{cases}\frac{f_{c}}{f_{b}}(1-X) c_{B}^{a m b} & X \geq X_{c r i t} \\
\frac{f_{c}}{f_{a}} X c_{A}^{i n} & X<X_{c r i t}\end{cases}
\end{gathered}
$$

\subsection{Numerical model}

The flow-through domain has dimensions of $1.5 \mathrm{~m} \times 0.35 \mathrm{~m} \times 0.35 \mathrm{~m}$ (length $\times$ width $\times$ height) and represents a hypothetical intermediate scale fully three-dimensional laboratory setup. The domain was discretized into 183750 cells, with the cell size of $0.01 \mathrm{~m}$ in each direction. The flow-through system was described as a confined aquifer. Flow was solved applying a cell-centered finite volume method. Constant flow boundary conditions were set at the inlet and at the outlet of the flow-through domain. Injection and extraction of solutions at the inlet and outlet of the flow-through setup was simulated with 49 cells representing injection and extraction ports. No-flow was imposed at the other boundaries of the system. A particle tracking algorithm based on Pollock's scheme (1988), was used to compute the streamlines, using 60025 particles released at the inlet. Steady-state transport was simulated with the method recently proposed by Cirpka et al. (2015), solving for advective transport along the streamlines and dispersive mass exchange in the transverse direction. At each cross section perpendicular to the longitudinal direction $x$, transverse dispersion was computed by Finite Volume approach on Voronoi polygons for each streamline. To simulate continuous injection, a constant mass flux was set at the inlet whereas no flux conditions were set at the top, side, and bottom boundaries. The plumes of conservative tracer or reactant A were injected at the central inlet port, whereas pure water or a solution containing reactant B was injected from the surrounding inlet ports.

As shown in Figure 1a, a heterogeneous anisotropic inclusion was inserted in the otherwise 
157 homogeneous matrix. The hydraulic conductivity of the matrix was $2.5 \times 10^{-3} \mathrm{~m} / \mathrm{s}$. The inclusion had a dimension of $0.90 \mathrm{~m} \times 0.12 \mathrm{~m} \times 0.12 \mathrm{~m}$. The inclusion consisted of two layers with alternating angled slices of coarse and fine porous media (Figure 1b). In order to achieve macroscopic anisotropy, the direction of the angled slices were opposite between the two layers. Figure 1c shows a 2-D view of the bottom layer: the angle between the slices and the flow direction is indicated by $\alpha\left[^{\circ}\right]$, whereas $s[\mathrm{~L}]$ represents the spacing of the slices. The fine material of the inclusion (i.e., indicated by a blue color in Figures $1 \mathrm{~b}$ and $1 \mathrm{c}$ ) had the same permeability of the matrix, whereas the coarse material (i.e., yellow in Figures $1 \mathrm{~b}$ and $1 \mathrm{c}$ ) had a higher hydraulic conductivity of $3.06 \times 10^{-2} \mathrm{~m} / \mathrm{s}$ or $3.03 \times 10^{-1} \mathrm{~m} / \mathrm{s}$, resulting in a permeability contrast $\left(k_{\text {contr }}[-]\right)$ of 12.5 or 121 , respectively. The grain diameters of the materials were directly related to their permeability according to the relation of Hazen (1892), i.e., $K=(C d)^{2}$, where $C=100 \mathrm{~m}^{-0.5} \mathrm{~s}^{-0.5}$. Porosity was set as 0.4 for both the fine and coarse porous media.

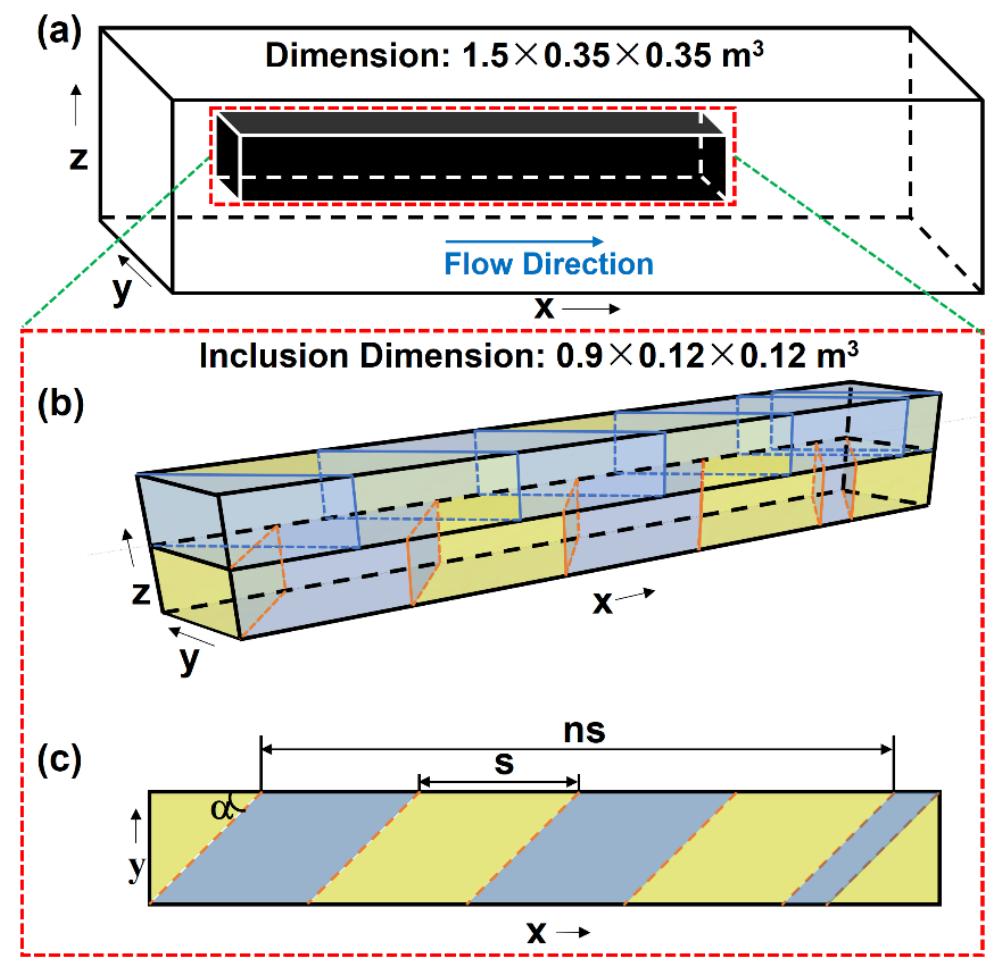

Fig. 1 Geometry of the 3-D setup: a) overview of the domain; b) anisotropy structure of the inclusion; c) top view of the bottom layer of the inclusion, the top layer has an identical 
structure but an opposite direction of the slices. Yellow color: high permeability medium; Blue color: low permeability medium; $\alpha$ : angle between the slice and the main flow direction; $s$ : distance between the slices.

Different anisotropy structures were designed by varying $\alpha, s$, and $k_{\text {contr }}$, but maintaining identical total volumes of high- and low-permeability materials, as well as the position of the inclusion, which was aligned with the central injection port and started at $0.20 \mathrm{~m}$ in the $x$ direction. Fifty different heterogeneous anisotropic structures were constructed with the parameters values of $\alpha, s$, and $k_{\text {contr }}$ listed in Table 1 . Notice, that when $\alpha$ equals to 0 or 90 degrees, the heterogeneous inclusion becomes macroscopically isotropic.

Table 1 Values of $\alpha, s$ and $k_{\text {contr }}$ used for the construction of the inclusion.

\begin{tabular}{ll}
\hline Parameter & Value \\
\hline$\alpha$ & $0^{\circ}, 11.25^{\circ}, 22.5^{\circ}, 45^{\circ}, 90^{\circ}$ \\
$\mathrm{s}$ & $0.03 \mathrm{~m}, 0.05 \mathrm{~m}, 0.10 \mathrm{~m}, 0.15 \mathrm{~m}, 0.25 \mathrm{~m}$ \\
$k_{\text {contr }}$ & $12.25,121$ \\
\hline
\end{tabular}

The simulations were performed at average seepage velocities of $3 \mathrm{~m} / \mathrm{d}$ and $0.3 \mathrm{~m} / \mathrm{d}$, thus resulting in 100 scenarios. For conservative transport a solute with the same aqueous diffusivity as fluorescein $\left(D_{a q}=0.48 \times 10^{-9} \mathrm{~m}^{2} / \mathrm{s}\right)$ was used. In selected cases, focusing on the compound-specific dispersion effects in helical flows, multitracer transport simulations were run considering an additional solute with the diffusivity of oxygen $\left(D_{a q}=1.97 \times 10^{-9} \mathrm{~m}^{2} / \mathrm{s}\right)$. Species with the aqueous diffusivities values of fluorescein and oxygen were also considered for the evaluation of the compound-specific behavior during mixing-controlled reactive transport.

\subsection{Entropy balance and metrics of mixing}


Approaches based on the Shannon entropy have been developed and applied in different fields of geosciences and engineering (e.g., Bianchi and Pedretti 2017; Cabeza and Karunanithi 2008; Kitanidis 1994; Singh 1997). In particular, for solute transport in porous media such approaches are powerful tools to quantify the dilution of solute plumes (e.g., Aquino and Bolster 2017; Beckie 1998; de Barros et al. 2015; Dentz et al. 2011; Kapoor and Kitanidis 1996; Kitanidis 1994; Paster et al. 2015; Rolle and Kitanidis 2014; Thierrin and Kitanidis 1994; Ursino 2001). Considering a flux-related framework, the transport equation of the entropy density of a conservative solute reads as (Chiogna et al. 2011):

$$
\mathbf{v} \cdot \nabla\left(-p_{Q} \ln p_{Q}\right)-\nabla \cdot\left(\mathbf{D} \nabla\left(-p_{Q} \ln p_{Q}\right)\right)=\frac{1}{p_{Q}} \nabla p_{Q}{ }^{T} \mathbf{D} \nabla p_{Q}
$$

where $p_{Q}=\frac{c}{\int_{\Omega} c q_{x} d A}\left[\mathrm{TL}^{-3}\right]$ is the flux-weighted probability density function of the solute mass, and $q_{x}\left[\mathrm{LT}^{-1}\right]$ is the specific-discharge in $x$ direction. The term on the right hand side of Eq. 5 represents a positive source of entropy due to dilution.

It is also interesting to consider the governing transport equation for the entropy density of a reactive species, which can be written as (Chiogna et al. 2012):

$$
\mathbf{v} \cdot \nabla\left(-p_{Q} \ln p_{Q}\right)-\nabla \cdot\left(\mathbf{D} \nabla\left(-p_{Q} \ln p_{Q}\right)\right)=-\left(1+\ln p_{Q}\right) r^{*}+\frac{1}{p_{Q}} \nabla p_{Q}{ }^{T} \mathbf{D} \nabla p_{Q}
$$

where the reactive term $r^{*}$ is defined as $r^{*}=\left(\frac{\partial p_{Q}}{\partial c}-\frac{1}{r} \frac{\partial^{2} p_{Q}}{\partial c^{2}} \nabla c^{T} \mathbf{D} \nabla c\right) r$.

Comparing Eq. 5 and Eq. 6 it can be noticed that an additional term on the right hand side appears for the reactive transport case. This term represents the contribution of reactive mixing, which can act as a sink in the entropy transport. The balance between entropy sources and sinks provides relevant insights on the interplay between dilution and reactive processes.

The flux-related dilution index, $E_{Q}$, is an entropy-based metric of mixing that has been 
proposed to quantify dilution of conservative plumes continuously emitted from a contaminant source (Rolle et al. 2009). This quantity represents an effective volumetric discharge that transports the solute mass flux at a given cross-section along the main flow direction and has been applied as metric of mixing in experimental and modeling studies (e.g., Ballarini et al. 2013; Cirpka et al. 2015; Rolle et al. 2013b). Mathematically, the flux-related dilution index is defined as the exponential of the Shannon entropy, in analogy to the volumetric dilution index introduced by Kitanidis (1994) for a solute slug:

$$
E_{Q}(x)=\exp \left(-\int_{\Omega}\left(p_{Q}(x, y, z) \ln p_{Q}(x, y, z)\right) q_{x}(x, y, z) d A\right)
$$

where $\Omega$ is the cross-section perpendicular to the longitudinal direction $x$.

The rate of increase of the natural logarithm of flux-related dilution index corresponds to the rate of increase of the entropy in the mean flow direction $x$ (i.e., integration of Eq. 5 over $\Omega$ for a conservative solute) and reads as (Chiogna et al. 2011, 2012):

$$
\frac{d \ln \left(E_{Q}\right)}{d x}=\int_{\Omega} \frac{1}{p_{Q}} \nabla p_{Q}{ }^{T} \mathbf{D} \nabla p_{Q} d \Omega
$$

The flux-related dilution index and its rate of increase can also be computed for a reactant. In this case, $E_{Q}(x)$ is no more a monotonically increasing function with the travel distance but its trend is determined by the balance between the entropy source and sink terms due to dilution and reactive processes (Eq. 6). For reactive transport, an additional metric of mixing that is considered in this study is the critical dilution index (i.e., $\left.C D I\left[\mathrm{~L}^{3} \mathrm{~T}^{-1}\right]\right)$. The $C D I$ is defined as the mixing amount required for the complete degradation of a reactive plume (i.e., species $A$ in our study) undergoing an instantaneous bimolecular reaction (Chiogna et al. 2011). The value of the $C D I$ is equal to the flux-related dilution index of a conservative plume at the distance $L$ from the source (i.e., $C D I=E_{Q}(L)$ ), where $L[\mathrm{~L}]$ is the length of the reactive plume. Analytical expressions can be derived for the $C D I$ in homogeneous domains. A simple first-order approximation for the $C D I$ in a three-dimensional system was derived in a previous 
study (Ye et al. 2016) and reads as:

$$
C D I_{\text {theor }}=\frac{E_{Q}(0)}{X_{\text {crit }}} \exp (1)
$$

\section{Results and Discussion}

\subsection{Conservative transport}

237

Different patterns of twisting streamlines caused by the different anisotropic structures were observed in the particle-tracking simulations. Furthermore, the outcomes of the conservative transport modeling resulted in plumes with reduced peak concentration and a monotonic entropy increase along the main flow direction. As an illustrative example, Figure 2 shows the results for the setup with $\alpha, s, k_{\text {contr }}$ and $v$ equal to $22.5^{\circ}, 0.10 \mathrm{~m}, 12.25$, and $3 \mathrm{~m} / \mathrm{d}$, respectively. Streamlines (49 black lines in Figure 2a) traced from the central inlet port are straight until they reach the anisotropic inclusion. At the inclusion, the streamlines are focused due to the presence of the high-permeability medium and follow a twisting pattern induced by the geometric structure of the inclusion. The complex three-dimensional flow due to the macroscopic anisotropic inclusion has a remarkable impact on solute transport. In fact the plume, continuously injected from the central inlet port, is strongly deformed, stretched and squeezed as can be observed in two-dimensional concentration distribution maps at different cross sections (Figure 2b). The streamlines twisting can also cause the plume to split into different parts (e.g., $x=0.65 \mathrm{~m}$ ), each with its own peak concentration. The twisting flow behavior deforms the material surface of the plume and favors the contact and the diffusive/dispersive mass exchange between the plume and the surrounding clean water. This leads to an enhancement of plume dilution that, as quantified by the flux-related dilution index, is particularly pronounced at the location of the macroscopic anisotropic inclusion (Figure 2c). 


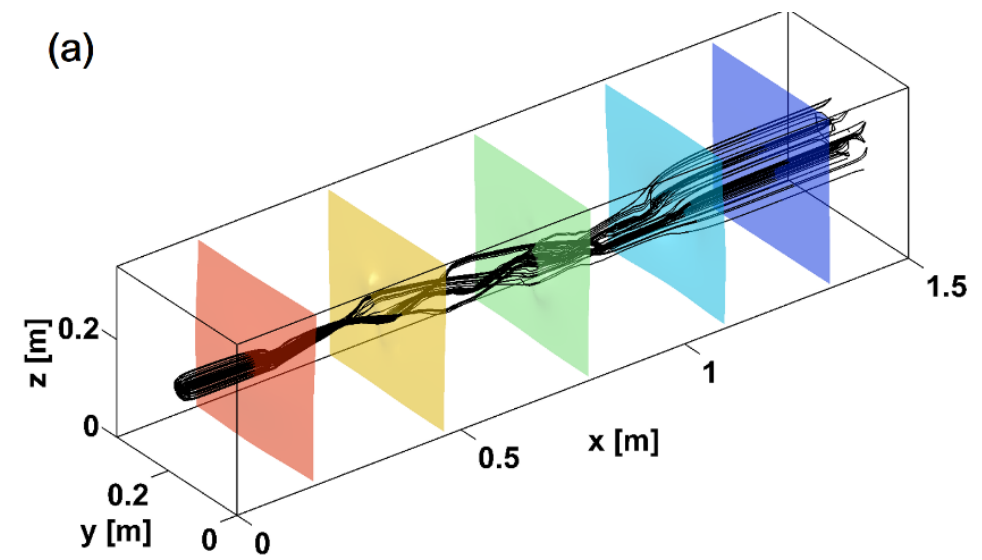

(c)

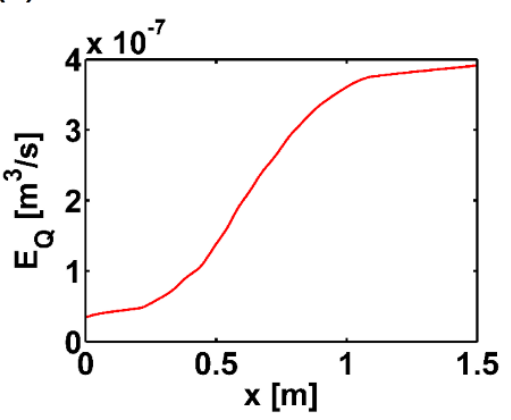

(b) $\mathrm{x}=0.05 \mathrm{~m}$
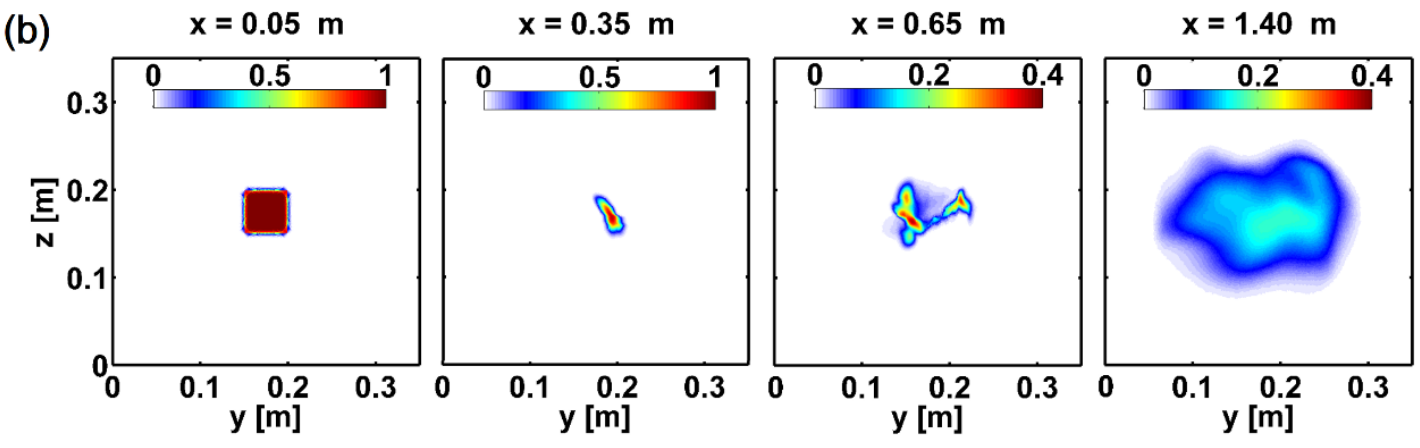

Fig. 2 Flow and transport in a heterogeneous anisotropic setup $\left(s=0.10 \mathrm{~m}, \alpha=22.5^{\circ}\right.$, $k_{\text {contr }}=12.25, v=3 \mathrm{~m} / \mathrm{d}$ ): a) Streamlines traced from the central inlet show a twisting pattern; black lines: streamlines; colored surfaces: isosurfaces of hydraulic head; b) Concentration distribution at different cross-sections; c) Flux-related dilution index along the travel distance.

Plume dilution was computed for all 100 conservative transport scenarios simulated, based on the parameters listed in Table 1, at seepage velocities of 3 and $0.3 \mathrm{~m} / \mathrm{d}$. Figure 3 shows the computed $E_{Q}$ values at the outlet of the flow-through domain. The results are visualized as four matrices, corresponding to the two seepage velocities and permeability contrasts. Each matrix contains the outcomes of simulations in which the angle of the slices (along the columns) and their distances (along the rows) were systematically changed. The difference of the anisotropy structure has a strong impact on plume dilution and leads to different values of flux-related dilution index at the outlet. Notice that, for the setups with an angle of $90^{\circ}$ or $0^{\circ}$, the streamlines do not twist, the material surface of the plume is not significantly deformed, and dilution is smaller compared to the anisotropic setups. The results show that, for a 
specified seepage velocity and permeability contrast, there is an optimal configuration of the anisotropy structure that maximizes the dilution enhancement. For instance, in the setups with a permeability contrast of 12.25 , the maximum dilution is achieved at $\alpha=22.5^{\circ}$ and $s=0.10 \mathrm{~m}$. In contrast, the maximum dilution is reached for the configuration of $\alpha=22.5^{\circ}$ and $s=0.05 \mathrm{~m}$ for the permeability contrast of 121 .
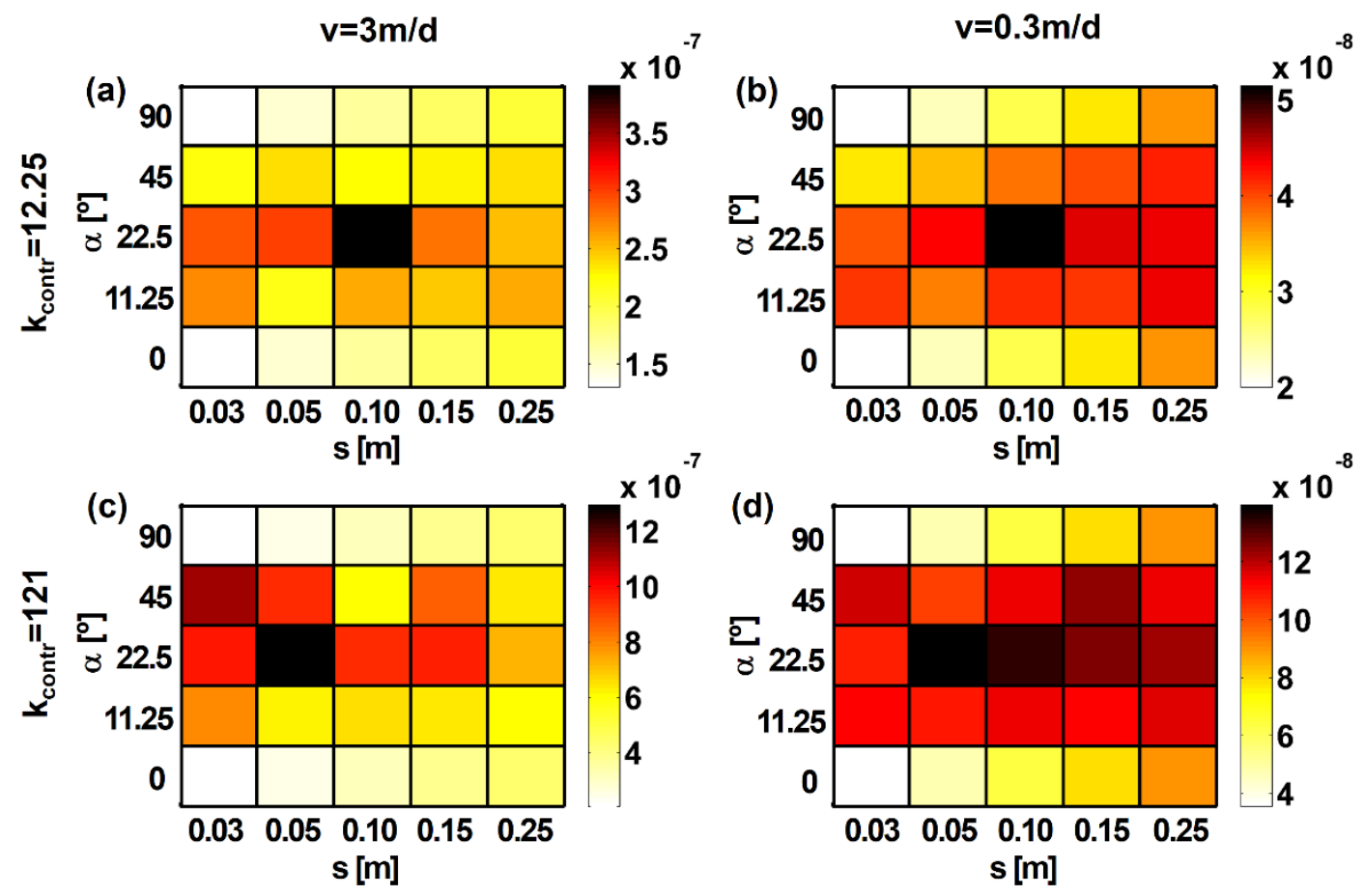

Fig. 3 Flux-related dilution index at the outlet of the domain for different heterogeneous anisotropic setups: a) $v=3 \mathrm{~m} / \mathrm{d}, k_{\text {contr }}=12.25$; b) $v=0.3 \mathrm{~m} / \mathrm{d}, k_{\text {contr }}=12.25$; c) $v=3 \mathrm{~m} / \mathrm{d}, k_{\text {contr }}=121$; d) $v=0.3 \mathrm{~m} / \mathrm{d} ; k_{\text {contr }}=121$. Both the magnitude of the seepage velocity and the permeability contrast affect plume dilution. As shown in Figure 3, for a given permeability contrast, dilution is larger at $3 \mathrm{~m} / \mathrm{d}$ than at $0.3 \mathrm{~m} / \mathrm{d}$, since transverse dispersion, which controls plume dilution, depends on the flow velocity. Similarly, for a given value of seepage velocity, a larger permeability contrast enhances diffusive/dispersive mass exchange between the plume and the surrounding solution, thus resulting in stronger plume dilution. 
To illustrate the development of the plume entropy along the travel distance, we consider selected scenarios with flow velocity of $3 \mathrm{~m} / \mathrm{d}$ and $k_{\text {contr }}$ of 12.25 . The cases correspond to the row $\left(\alpha=22.5^{\circ}\right)$ and the column $(s=0.10 \mathrm{~m})$ in Figure 3a, containing the scenario with maximum plume dilution. Figure 4 shows the flux-related dilution index and its rate of increase along the flow direction for the selected cases. The monotonic increase of the plume entropy is strongly affected by the geometry (both angle and spacing) of the anisotropic inclusion. For instance, Figure $4 \mathrm{a}$ shows that the flux-related dilution index in the scenario with the heterogeneous slices are inclined at $22.5^{\circ}$ is more than double with respect to the $90^{\circ}$ case. The rate of increase of the flux-related dilution index (Eq. 8) is also illustrative of the complex mixing dynamics induced by the twisting flows in the different anisotropic setups (Figure $4 \mathrm{c}$ and $4 \mathrm{~d}$ ). After an initial decrease and stabilization of $\mathrm{d} \ln E_{Q} / \mathrm{d} x$ in the homogeneous matrix due to flow defocusing effect from the inlet port, an interesting pattern with significant increase of plume dilution is apparent as the plume reaches the anisotropic inclusion. Several peaks of dilution enhancement are related to the geometry of the heterogeneous anisotropic inclusion and to the helical pattern of the streamlines. For instance, in the case of different angles (Figure 4c), plume focusing and twisting yields more pronounced peaks of $\mathrm{d} \ln E_{Q} / \mathrm{d} x$ resulting in stronger dilution enhancement. Such number of peaks that can be considered "hot spots of mixing", associated with the occurrence of plume focusing and twisting within the anisotropic inclusion also depends on the spacing between the alternating slices of fine and coarse material (Figure 4d). The rate of increase of the dilution index is positive in the whole domain since its expression corresponds to the source term in the entropy density balance for a conservative solute (Eq. 5). The overall trend shows progressively lower rates of increase for $E_{Q}$ within the anisotropic inclusion. Such behavior can be explained by the stronger concentration gradients as the plume reaches the inclusion and their attenuation further downstream as the plume becomes progressively more diluted. In fact, as expressed by Eq. 8, the rate of increase of the flux-related dilution index depends on the transverse dispersion 

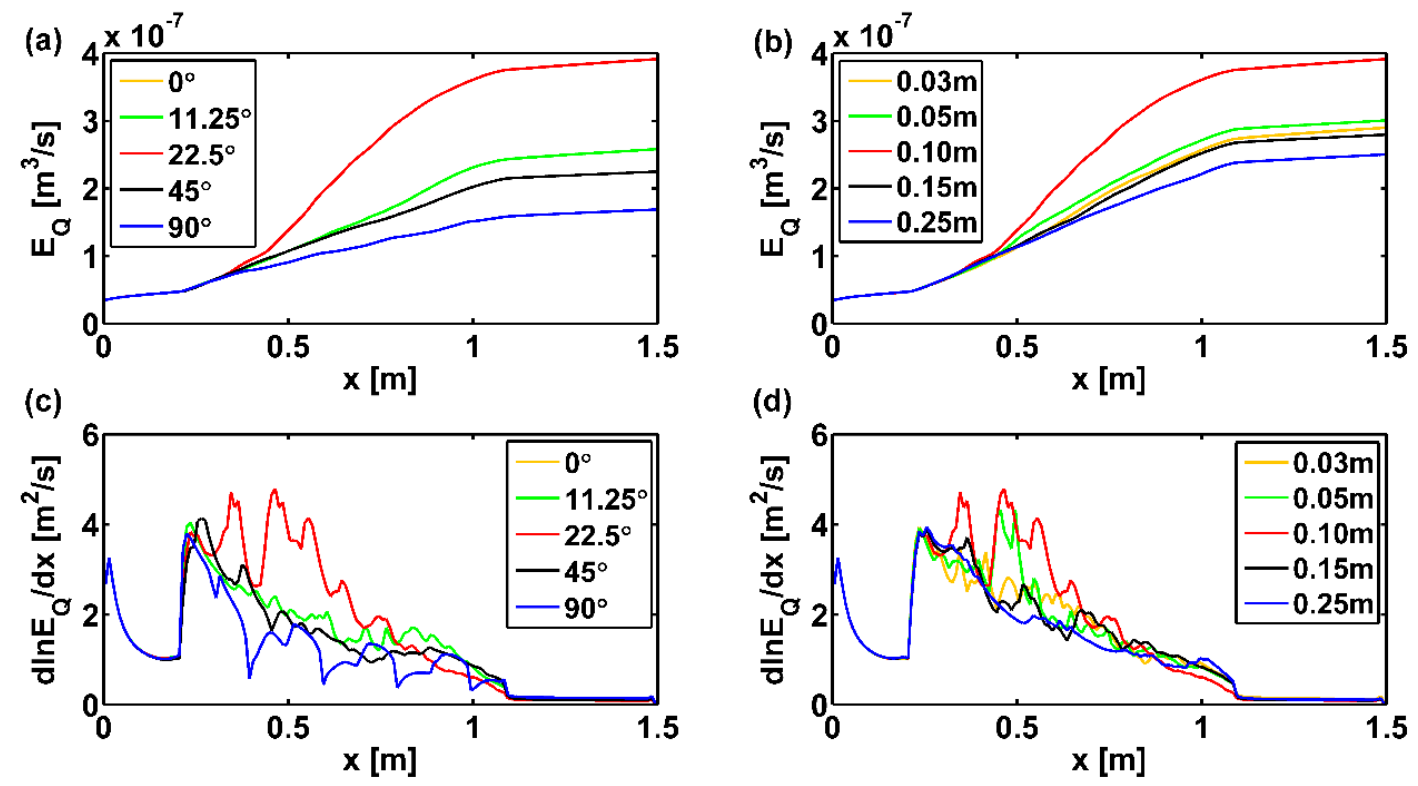

Fig. 4 Flux-related dilution index along the travel distance for selected setups with $v=3 \mathrm{~m} / \mathrm{d}$, $k_{\text {contr }}=12.25$ : a) $s=0.10 \mathrm{~m}$; b) $\alpha=22.5^{\circ}$. Rate of increase of the flux-related dilution index for the same scenarios: c) $s=0.10 \mathrm{~m}$; d) $\alpha=22.5^{\circ}$.

Figures $5 \mathrm{a}$ and $5 \mathrm{~b}$ show the dilution at the outlet for the setups at an average flow velocity of $3 \mathrm{~m} / \mathrm{d}$ and considering a permeability contrast of 12.25 and 121 , respectively. The colored bars represent the minimum, average and maximum dilution achieved in the anisotropic setups, while the black bar is the dilution obtained in a corresponding homogeneous isotropic system. The average value of $E_{Q}$ obtained in the heterogeneous anisotropic setups are $225 \%$ and $930 \%$ larger for the cases with a permeability contrast of 12.25 and 121 , respectively, compared to the homogeneous setup. The maximum relative differences of $E_{Q}$ (i.e., relative difference between the red and black bars) are $388 \%$ and $1516 \%$ for the permeability contrast of 12.25 and 121 , respectively. Even the minimum relative differences of $E_{Q}$ (i.e., relative difference between the blue and black bars) show a significant dilution enhancement $(172 \%$ and $662 \%$ for the cases with a permeability contrast of 12.25 and 121 , respectively) in the presence of a heterogeneous anisotropic inclusion. 

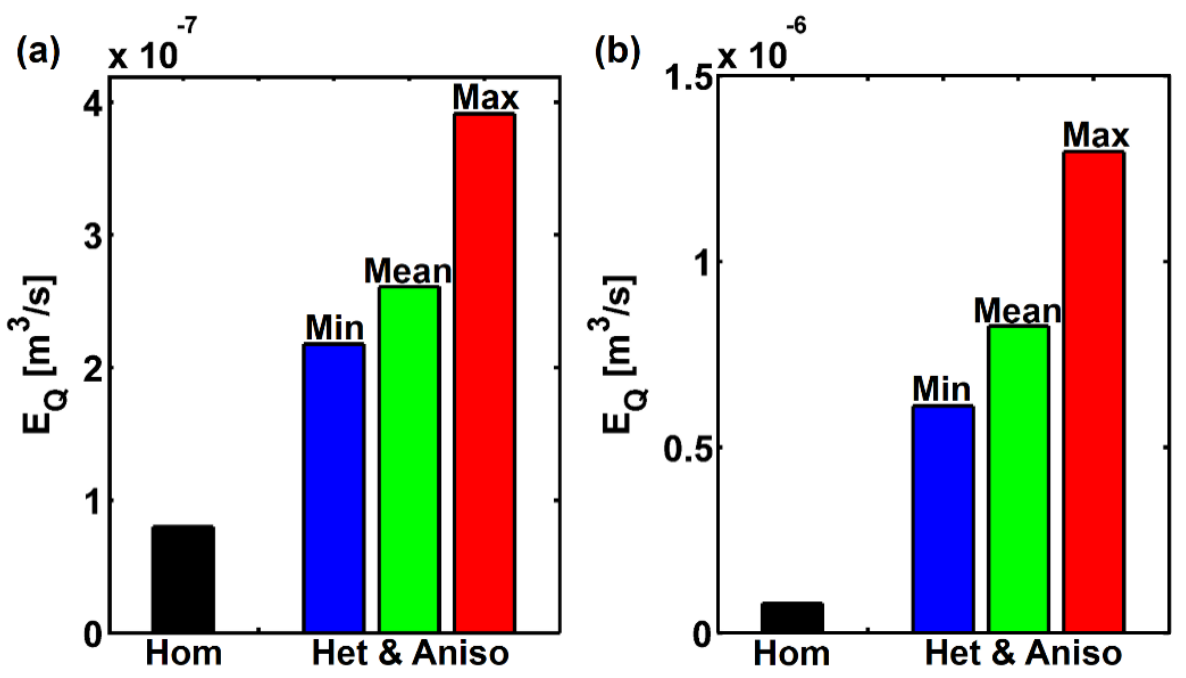

Fig. 5 Flux-related dilution index at the outlet for the cases: a) $v=3 \mathrm{~m} / \mathrm{d}, k_{\text {contr }}=12.25$ (25 scenarios); b) $v=3 \mathrm{~m} / \mathrm{d}, k_{\text {contr }}=121$ (25 scenarios). Hom: Homogeneous setup; Het\&Aniso: Heterogeneous anisotropic setup with angled slices (Min: Minimal value; Mean: Mean value; Max: Maximum value).

To investigate compound-specific effects in helical flows, multitracer conservative transport simulations were performed considering an additional tracer with the diffusivity of oxygen. Such simulations were run for the cases of minimal and maximum entropy illustrated in Figure 4. Figure 6 shows the flux-related dilution index and the spatial derivative of its natural logarithm along the flow direction for both solutes. In Figures $6 a$ and $6 b$, oxygen (i.e., with higher diffusivity) is more diluted than fluorescein (i.e., with lower diffusivity), which is consistent with the effect shown in isotropic porous media. The entropy of the solutes increases with a similar pattern in a specific anisotropy configuration (see Figures $6 \mathrm{c}$ and $6 \mathrm{~d}$ ). The difference of dilution between the two solutes depends on the specific value of $\mathrm{d} \ln E_{Q} / \mathrm{d} x$, particularly at the beginning of the inclusion where the plumes focus and twist within the heterogeneous anisotropic structure and the compound-specific diffusivities control lateral mass exchange. 

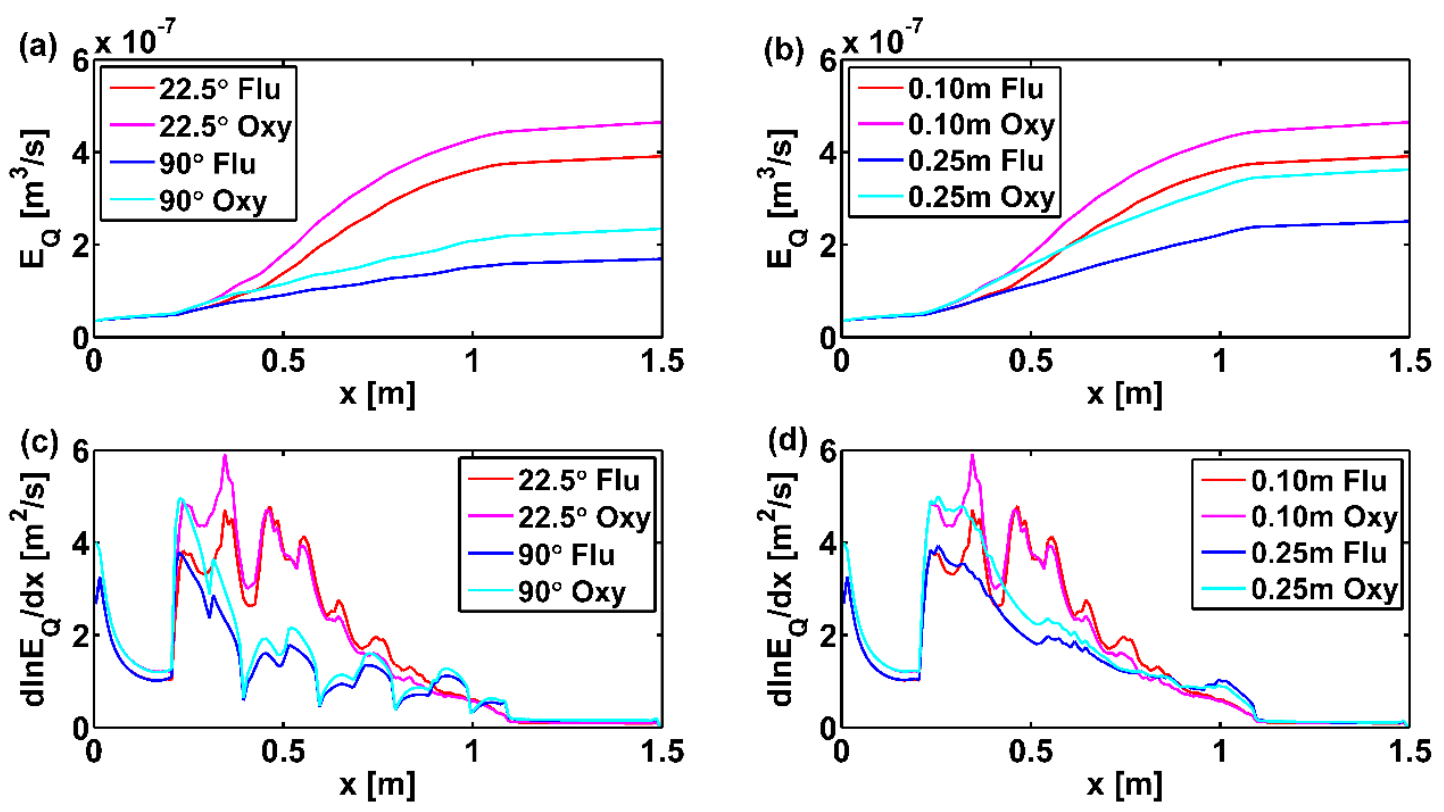

Fig. 6 Flux-related dilution index along the travel distance using two tracers with aqueous diffusivity of fluorescein and oxygen: a) $s=0.10 \mathrm{~m}$; b) $\alpha=22.5^{\circ}$. Rate of increase of the flux-related dilution index for the same scenarios: c) $s=0.10 \mathrm{~m}$; d) $\alpha=22.5^{\circ}$.

\subsection{Reactive transport}

Reactive transport was investigated considering the same scenarios analyzed for conservative transport. Figure 7 shows an example of mixing-controlled reactive transport in which the plumes of the reactant $A$ and product $C$ are visualized in a heterogeneous anisotropic domain. The simulation was performed with a critical mixing ratio of 0.05 , considering a source concentration of reactant $A\left(c_{A}^{i n}\right)$ of 19 and an initial concentration of reactant $B\left(c_{B}^{a m b}\right)$ of 1 in the ambient water. The reactant $A$ is not significantly consumed in the initial portion of the domain (i.e., at $x<0.2 \mathrm{~m}$ ). When the plumes reach the inclusion, the concentration of $A$ reduces drastically and the plume surfaces of both $A$ and $C$ are deformed due to the twisting flow pattern. After the inclusion (i.e., at $x>1.1 \mathrm{~m}$ ), the flow in the matrix becomes uniform again and also the reactive plumes have a more regular shape, as shown by the concentration distributions in the down gradient cross-sectional planes (i.e., last two $y$-z cross sections in 
(a)

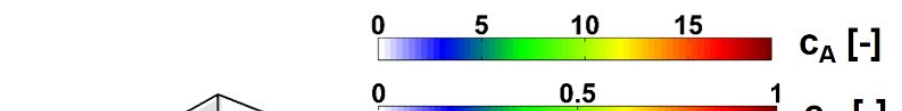

(b)

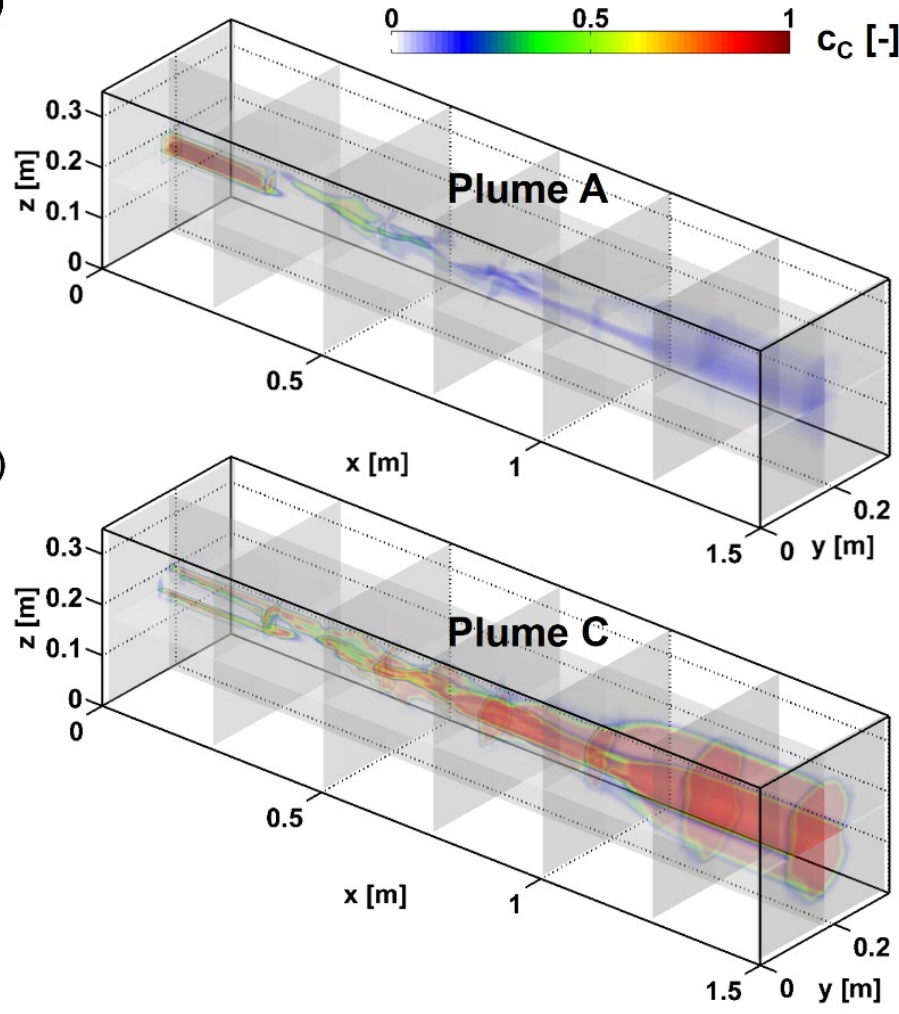

Fig. 7 Plumes computed for a mixing-controlled reactive transport simulation in a heterogeneous anisotropic domain: a) reactant $A$; b) product $C$.

Also for mixing-controlled reactive transport we considered 100 scenarios based on the geometric parameters and permeability contrasts of the anisotropic inclusion listed in Table 1, as well as the seepage velocities of 3 and $0.3 \mathrm{~m} / \mathrm{d}$. With the aim of analyzing the critical dilution index $(C D I)$ in the different anisotropic setups, we considered both reactants with the aqueous diffusivity of fluorescein and with dimensionless inlet concentration of 0.3 and 1 for reactant $A$ and reactant $B$, respectively. This corresponds to a critical mixing ratio of 0.77 and results in steady-state plume lengths for the reactant $A$ ending within the considered three-dimensional domain. The values of critical dilution index were calculated based on the flux-related dilution index of a conservative tracer at the end of the reactive plume. The results are shown in Figure 8 for the considered seepage velocities and permeability contrasts. 
The critical dilution index is very similar in all scenarios (4\% relative difference) showing that also in the case of complex three-dimensional flow in anisotropic setup the value of the critical dilution index does not depend significantly on the heterogeneity and anisotropy of the system. The outcomes of the numerical simulations were also compared with the theoretical value of the critical dilution index, $C D I_{\text {theor }}($ Eq. 9). The comparison yields satisfactory results (average relative difference of $10 \%$ ), although the first order approximation expressed by Eq. 9 (gray surface in Figure 8) tends to slightly overestimate the mixing needed for the complete degradation of a reactive plume compared to the values computed with the numerical model. Such discrepancy stems from the assumption of sufficiently long plumes (i.e., small $X_{c r i t}$ ) in the derivation of the analytical expression (Ye et al. 2016).
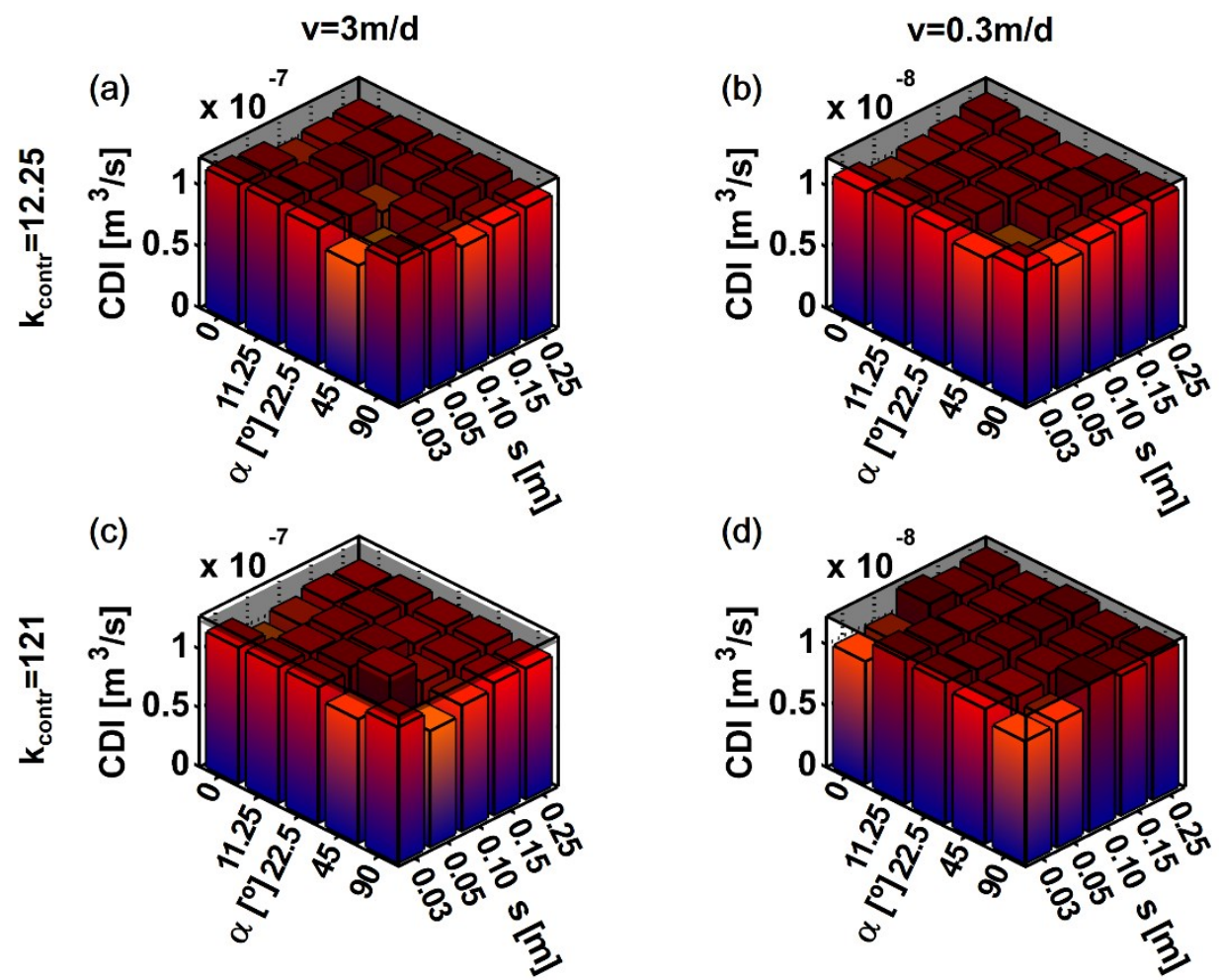

Fig. 8 Critical dilution index for the different heterogeneous anisotropic setups: a) $v=3 \mathrm{~m} / \mathrm{d}$, $k_{\text {contr }}=12.25$; b) $v=0.3 \mathrm{~m} / \mathrm{d}, k_{\text {contr }}=12.25$; c) $v=3 \mathrm{~m} / \mathrm{d}, k_{\text {contr }}=121$; d) $v=0.3 \mathrm{~m} / \mathrm{d} ; k_{\text {contr }}=121$. Gray surface: theoretical critical dilution index.

Figure 9 shows the flux-related dilution index of reactant $A$ (indicated as $E_{Q}[A]$ ) and its 
spatial derivative in the same setups selected for the illustration of plume dilution in the case of conservative transport (Figure 4). Here $c_{A}^{i n}$ was set to 0.9 and $c_{B}^{a m b}$ was kept as 1 , yielding $X_{\text {crit }}=0.53$. Since the reaction is instantaneous and the source concentration of $A$ is low, the flux-related dilution index is decreasing in all setups indicating that the reactive sink term dominates the entropy density balance for reactive transport (Eq. 6). This is also substantiated by the negative values of $\mathrm{d} \ln E_{Q}[A] / \mathrm{d} x$ (Figures 9c and 9d). For mixing-controlled reactive transport, a stronger dilution of conservative solute, caused by the focusing and twisting flow (Figure 4), corresponds to a faster consumption of reactant $A$ in Figure 9. For instance, in the case of $\alpha=22.5^{\circ}$, the plume of reactant $A$ is almost three times shorter than the analogous case with $\alpha=90^{\circ}$ (Figure 9a). In fact, local enhancements of transverse mixing directly imply reaction enhancements and shorter plumes of reactant $A$.

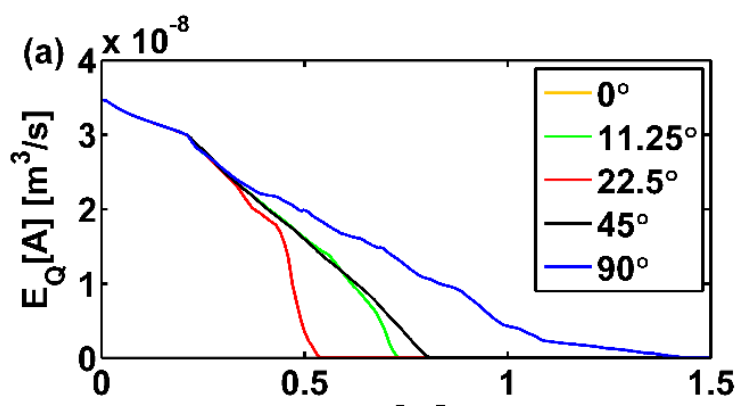

(c)

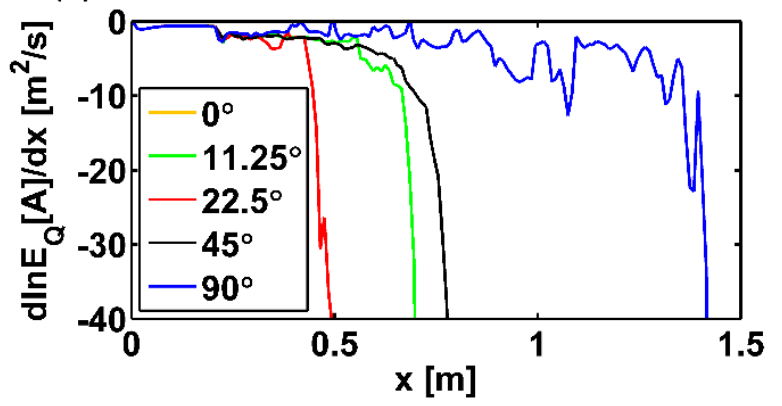

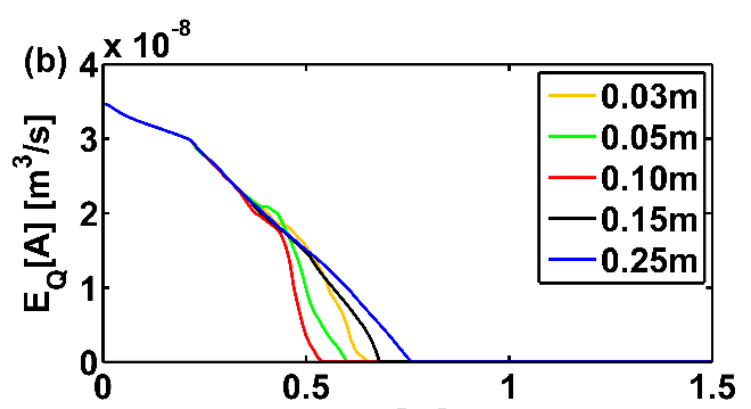

(d)

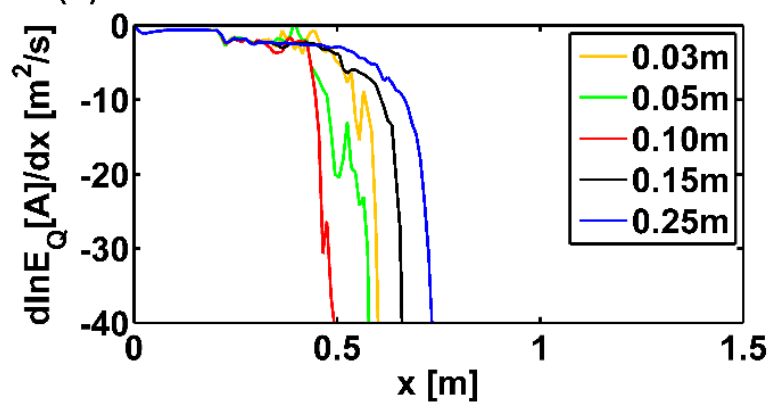

Fig. 9 Flux-related dilution index of reactant $A$ along the travel distance for selected setups with $v=3 \mathrm{~m} / \mathrm{d}, k_{\text {contr }}=12.25$ : a) $s=0.10 \mathrm{~m}$; b) $\alpha=22.5^{\circ}$. Rate of increase of the flux-related dilution index for reactant $A$ in the same scenarios: c) $s=0.10 \mathrm{~m}$; d) $\alpha=22.5^{\circ}$.

Compound-specific effects were also investigated for mixing-controlled reactive transport. 
We considered the scenarios examined above for the conservative tracer (Figure 6) and computed reactive transport considering reactive species both with aqueous diffusivity of fluorescein and oxygen. Figure 10 shows the results illustrated as flux-related dilution index of reactant $A$. In case of higher diffusivity, the reactant plume is shorter. Such
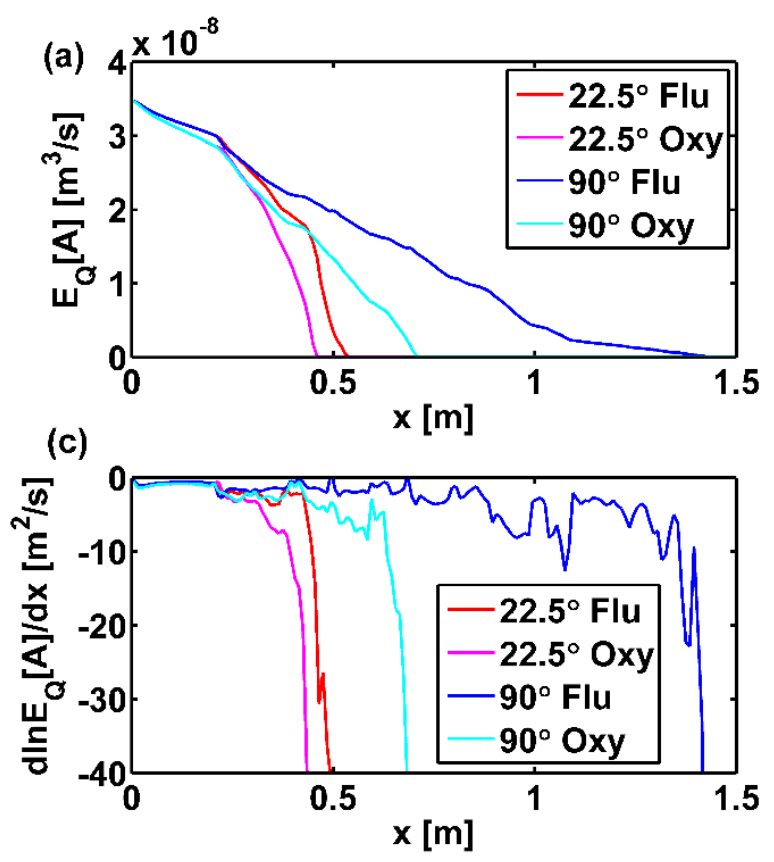

(c) significant mixing enhancement (i.e., cases for $\alpha=22.5^{\circ}$ ).

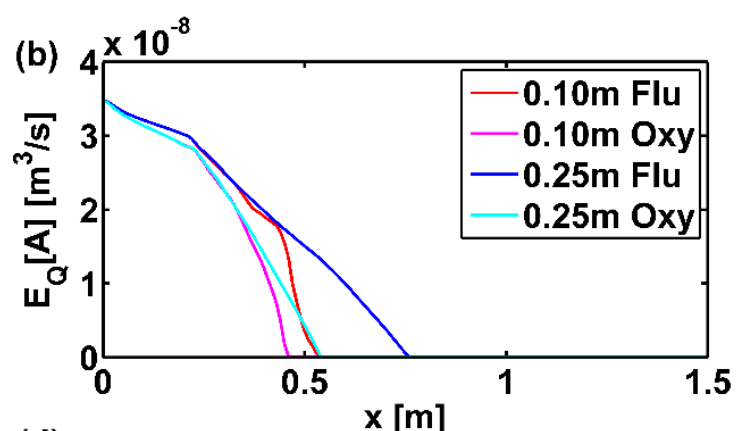

(d)

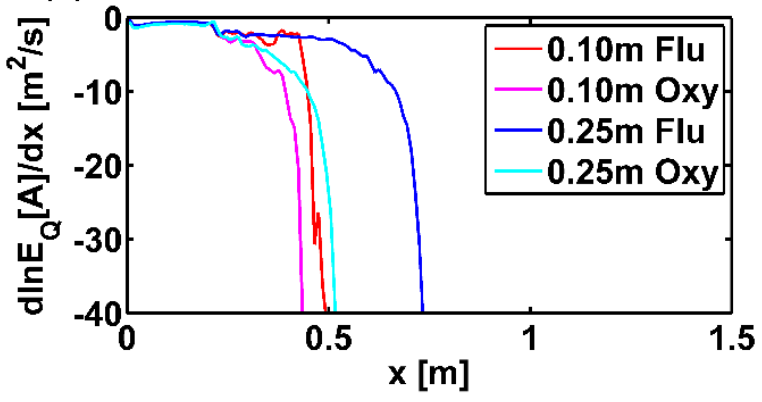
compound-specific effect is more important for the cases with less pronounced mixing enhancement and less important when mixing enhancement is maximized. This behavior can be attributed to more important kinematic effects and shorter residence times before complete plume degradation in the scenarios in which the anisotropic inclusion causes a more

Fig. 10 Compound-specific effects on the flux-related dilution index of reactant $A$ along the travel distance. The simulations were performed with reactants with aqueous diffusivities of fluorescein and oxygen: a) Scenarios with $s=0.10 \mathrm{~m}$ and b) $\alpha=22.5^{\circ}$. Rate of increase of the flux-related dilution index for reactant $A$ : c) $s=0.10 \mathrm{~m}$; d) $\alpha=22.5^{\circ}$.

\section{Summary and Conclusions}

In this work we have investigated the effect of anisotropy structures on conservative and 
mixing-controlled reactive transport in porous media. We have performed a large number of numerical simulations in fully three-dimensional heterogeneous anisotropic setups. In such setups, the geometrical configuration of macroscopic anisotropic inclusions cause complex flow fields, entailing twisting streamlines. Our results show that the anisotropy-induced secondary motion and the flow focusing due to permeability contrast have a major impact on plume dilution and reaction. By constructing 25 different anisotropy structures we could systematically investigate the effect of key geometrical parameters such as the angle orientation of alternating slices of fine and coarse materials with respect to the average flow velocity, as well as their spacing. The outcome of the analysis allowed identifying optimal anisotropic configurations maximizing mixing and reactions, and yielding substantial mixing enhancement compared to analogous simulations in homogeneous media. Entropy balance equations and entropy-based metrics of mixing provided an adequate framework to quantify the enhancement of dilution in the conservative transport scenarios and the enhancement of reactive mixing when reaction between two initially segregated reactants was considered. The analysis based on the concept of Shannon entropy also allowed us to establish a link between the complex flow field and the key phenomena of flow-focusing and streamlines twisting with the local increase of mixing. This was apparent for both conservative and reactive transport scenarios. For conservative transport the interpretation is more straightforward since the plume entropy monotonically increases along the travel distance; whereas for reactive transport the entropy balance depends on the relative impact of a source term due to physical dispersive mixing and a sink term entailing the effects of the chemical reaction.

This study contributes to improve the understanding of solute transport in complex fully three-dimensional flow in porous media. 3-D features such as helical patterns of streamlines have a strong impact on transport and mixing but cannot be observed in more conventional two-dimensional setups. The outcomes of this work have implications for applications in both 
natural and engineered systems. For instance, sedimentological observation of aquifer outcrops (e.g., Heinz et al. 2003) often shows more complex heterogeneous anisotropic patterns than those considered in common realizations of heterogeneous media for simulation of flow and contaminant transport in groundwater. In fact the latter are often based on two-dimensional representations and typically do not consider the effect of anisotropy. Moreover, in engineering applications it may be of interest to design devices, such as porous media static mixers, which can induce mixing and reaction between two initially segregated fluids and/or solutes. To this end, the outcomes of this study show the importance of the geometry and anisotropic structures, as well as the possibility to find configurations allowing maximizing plume dilution and reactive mixing. Further investigation is also necessary to develop upscaling rules for conservative and mixing-controlled reactive transport in complex flow fields. To this end, numerical flow and transport simulations in larger scales heterogeneous anisotropic domains could help finding effective upscaled parameters and contribute to fill the gap between laboratory and field observations.

\section{Acknowledgments}

This study was supported by the National Natural Science Foundation of China (51709085). Y. Ye acknowledges the support of "The Fundamental Research Funds for the Central Universities" (2017B00214) and a project funded by the Priority Academic Program Development of Jiangsu Higher Education Institutions. G. Chiogna acknowledges the support of the Stiftungsfonds für Umweltökonomie und Nachhaltigkeit $\mathrm{GmbH}$ (SUN). C. Lu acknowledges the support of the National Natural Science Foundation of China (51679067) and the "111 Project" (B17015), Ministry of Education and State Administration of Foreign

Experts Affairs, P. R. China. M. Rolle acknowledges the support of the Danish Council for Independent Research (DFF) and of the Sino-Danish Center. The authors would like to thank 
Prof. O.A. Cirpka for discussion on helical flows and for providing an earlier version of the code that has been used in this study.

\section{References}

Acharya, R.C., Valocchi, A.J., Werth, C.J., Willingham, T.W.: Pore-scale simulation of dispersion and reaction along a transverse mixing zone in two-dimensional porous media. Water Resour. Res. 43, W10435 (2007)

Amos, R.T., Berkins, B.A., Delin, G.N., Cozzarelli, I.M., Blowes, D.W., Kirshtein, J.D.: Methane oxidation in a crude oil contaminated aquifer: delineation of aerobic reactions at the plume fringes. J. Contam. Hydrol. 125, 13-25 (2011)

Aquino, T., Bolster, D.: Localized point mixing rate potential in heterogeneous velocity fields. Trans. Porous Medi. 119, 391-402 (2017)

Ballarini, E., Bauer, S., Eberhardt, C., Beyer, C.: Evaluation of the role of heterogeneities on transverse mixing in bench-scale tank experiments by numerical modeling. Ground Water 52, 368-377 (2013)

Bauer, R.D., Rolle, M., Bauer, S., Eberhardt, C., Grathwohl, P., Kolditz, O., Meckenstock, R.U., Griebler, C.: Enhanced biodegradation by hydraulic heterogeneities in petroleum hydrocarbon plumes. J. Contam. Hydrol. 105, 56-68 (2009)

Beckie, R. D.: Analysis of scale effects in large-scale solute transport models. In: Sposito, G. (eds.) Scale Dependence and Scale Invariance in Hydrology, pp. 314-334. Cambridge Univ. Press, New York (1998)

Bennett, J.P., Haslauer, C.P., Cirpka, O.A.: The impact of sedimentary anisotropy on solute mixing in stacked scour-pool structures. Water Resour. Res. 53, 2813-2832 (2017)

Bianchi, M., Pedretti, D.: Geological entropy and solute transport in heterogeneous porous media, Water Resour. Res., 53, 4691-4708 (2017)

Cabezas, H., Karunanithi, A.T.: Fisher information, entropy, and the second and third laws of thermodynamics. Ind. Eng. Chem. Res. 47, 5243-5249 (2008)

Castro-Alcala, E., Fernandez-Garcia, D., Carrera, J., Bolster, D.: Visualization of mixing processes in a heterogeneous sand box aquifer. Environ. Sci. Technol. 46, 3228-3235 (2012)

Chiogna, G., Eberhardt, C., Grathwohl, P., Cirpka, O.A., Rolle, M.: Evidence of 
compound-dependent hydrodynamic and mechanical transverse dispersion by multitracer laboratory experiments. Environ. Sci. Technol. 44, 688-693 (2010)

Chiogna, G., Cirpka, O.A., Grathwohl, P., Rolle, M.: Transverse mixing of conservative and reactive tracers in porous media: Quantification through the concepts of flux-related and critical dilution indices. Water Resour. Res. 47, W02505 (2011)

Chiogna, G., Hochstetler, D.L., Bellin, A., Kitanidis, P.K., Rolle, M.: Mixing, entropy and reactive solute transport. Geophys. Rev. Lett. 39, L20405 (2012)

Chiogna, G., Rolle, M., Alberto, B., Cirpka, O.A: Helicity and flow topology in three-dimensional anisotropic porous media. Adv. Water Resour. 73, 134-143 (2014)

Chiogna, G., Cirpka, O.A., Rolle, M., Alberto, B.: Helical flow in three-dimensional nonstationary anisotropic heterogeneous porous media. Water Resour. Res. 51, 261-280 (2015)

Chiogna, G., Cirpka, O.A., Herrera, P.A.: Helical flow and transient solute dilution in porous media. Transp. Porous Med. 111, 591-603 (2016)

Cirpka, O.A., Valocchi A.J.: Two-dimensional concentration distribution for mixing-controlled bioreactive transport in steady state. Adv. Water Resour. 30, 1668-1679 (2007)

Cirpka, O.A., de Barros, F.P.J., Chiogna, G., Rolle, M., Nowak, W.: Stochastic flux-related analysis of transverse mixing in two-dimensional heterogeneous porous media. Water Resour. Res. 47, W06515 (2011)

Cirpka, O.A., Rolle, M., Chiogna, G., de Barros, F.P., Nowak, W.: Stochastic evaluation of mixing-controlled steady-state plume lengths in two-dimensional heterogeneous domains. J. Contam. Hydrol. 138-139, 22-39 (2012)

Cirpka, O.A., Chiogna, G., Rolle, M., Bellin, A.: Transverse mixing in three-dimensional non-stationary anisotropic heterogeneous porous media. Water Resour. Res. 51, 241-260 (2015)

Crevacore, E., Tosco, T., Sethi, R., Boccardo, G., Marchisio, D.L.: Recirculation zones induce non-Fickian transport in three-dimensional periodic porous media. Phys. Rev. E 94, $053118(2016)$

de Anna, P., Jimenez-Martinez, J., Tabuteau, H., Turuban, R., Le Borgne, T., Derrien, M., Meheust, Y.: Mixing and reaction kinetics in porous media: an experimental pore scale quantification. Environ. Sci. Technol. 48, 508-516 (2014)

de Barros, F.P.J., Fiori, A., Boso, F., Bellin, A.: A theoretical framework for modling dilution enhancement of non-reactive solutes in heterogeneous porous media. J. Contam. Hydrol. 
175, 72-83 (2015)

de Dreuzy, J.R., Carrera, J., Dentz, M., Le Borgne, T.: Time evolution of mixing in heterogeneous porous media. Water Resour. Res. 48, W06511 (2012)

Dentz, M., Le Borgne, T., Englert, A., Bijeljic, B.: Mixing, spreading and reaction in heterogeneous media: A brief review. J. Contam. Hydrol. 120-121, 1-17 (2011)

Di Dato, M., de Barros, F.P.J., Fiori, A., Bellin, A.: Effects of the hydraulic conductivity microstructure on macrodispersivity. Water Resour. Res. 52, 6818-6832 (2016a)

Di Dato, M., Fiori, A., Chiogna, G., de Barros, F.P.J., Bellin, A.: Impact of the spatial structure of the hydraulic conductivity field on vorticity in three-dimensional flows. Proc. R. Soc. A. 472, The Royal Society (2016b)

Fox, D.T., Guo, L., Fujita, Y., Huang, H., Redden, G.: Experimental and numerical analysis of parallel reactant flow and transverse mixing with mineral precipitation in homogeneous and heterogeenosu porous media. Transp. Porous Med. 111, 605-626 (2016)

Hazen, A.: Some physical properties of sands and gravels with special reference to their use in filtration. Ann. Rep. State Board of Health Mass 24, 541-556 (1892)

Hemker, K., van den Berg, E., Bakker, M.: Ground water whirls. Ground Water 42, 234-242 (2004)

Hemker, K., Baker, M.: Analytical solutions for whirling groundwater flow in two-dimensional heterogeneous anisotropic aquifers. Water Resour. Res. 42, W12419 (2006)

Heinz, J., Kleineidam, S., Teutsch, G., Aigner, T.: Heterogeneity patterns of quaternary glaciofluvial gravel bodies (SW-Germany): Application to hydrogeology. Sediment. Geol. 158, 1-23 (2003).

Herrera, P.A., Valocchi, A.J., Beckie, R.D.: A multidimensional streamline-based method to simulate reactive solute transport in heterogeneous porous media. Adv. Water Resour. 33, 711-727 (2010)

Hochstetler, D.L., Rolle, M., Chiogna, G., Haberer, C.M., Grathwohl, P., Kitanidis, P.K.: Effects of compound-specific transverse mixing on steady-state reactive plumes: Insights from pore-scale simulations and Darcy-scaly experiments. Adv. Water Resour. 54, 1-10 (2013)

Icardi, M., Boccardo, G., Marchisio, D., Tosco, T., Sethi, R.: Pore-scale simulation of fuild flow and solute dispersion in three-dimensional porous media. Phys. Rev. E 90, 013032 (2014)

Jiménez-Martínez, J., de Anna, P., Tabuteau, H., Turuban, R., Le Borgne, T., Méheust, Y.: 
Pore-scale mechanisms for the enhancement of mixing in unsaturated porous media and implications for chemical reactions. Geophys. Res. Lett. 42, 5316-5324 (2015)

Kapoor, V., Kitanidis, P.K.: Concentration fluctuations and dilution in two-dimensionally periodic heterogeneous porous media. Transp. Porous Med. 22, 91-119 (1996)

Kitanidis, P.K.: The concept of dilution index. Water Resour. Res. 30, 2011-2026 (1994)

Liedl, R., Valocchi, A.J., Dietrich, P., Grathwohl, P.: Finiteness of steady state plumes. Water Resour. Res. 41, 3923-3929 (2005)

Liedl, R., Yadav, P.K., Dietrich, P.: Length of 3-D mixing-controlled plumes for a fully penetrating contaminant source with finite width. Water Resour. Res. 47, W08602 (2011)

Muniruzzaman, M., Haberer, C.H., Grathwohl, P., Rolle, M.: Multicomponent ionic dispersion during transport of elctrolytes in heterogeneous porous media: Experiments and model-based interpretation. Geochim. Cosmochim. Acta 141, 656-669 (2014)

Ottino, J.M.: The Kinematics of Mixing. Cambridge University, Cambridge (1989)

Paster, A., Aquino, T., Bolster, D.: Incomplete mixing and reactions in laminar shear flow. Phys. Rev. E 92, 012922 (2015)

Pedretti, D., Fernàndez-Garcia, Sanchez-Vila, X., Bolster, D., Benson, D.A.: Apparent directional mass-transfer capacity coefficients in three-dimensional anisotropic heterogeneous aquifers under radical convergent transport. Water Resour. Res. 50, 1205-1224 (2014)

Pollock, D.W.: Semianalytical computation of path lines for finite-difference models. Ground Water 26, 743-750 (1988)

Prommer, H., Anneser, B., Rolle, M., Einsiedl, F., Griebler, C.: Biogeochemical and isotopic gradients in a BTEX/PAH contaminant plume: Model-based interpretation of a high-resolution field data set. Environ. Sci. Technol. 43, 8206-8212 (2009)

Rolle, M., Eberhardt, C., Chiogna, G., Cirpka, O.A., Grathwohl, P.: Enhancement of dilution and transverse reactive mixing in porous media: experiments and model-based interpretation. J. Contam. Hydrol. 110, 130-142 (2009)

Rolle, M., Hochstetler, D., Chiogna, G., Kitanidis, P.K., Grathwohl, P.: Experimental investigation and pore-scale modeling interpretation of compound-specific transverse dispersion in porous media. Transp. Porous Med. 93, 347-362 (2012)

Rolle, M., Chiogna, G., Hochstetler, D.L., Kitanidis, P.: On the importance of diffusion and compound-specific mixing for groundwater transport: An investigation from pore to field scale. J. Contam. Hydrol. 153, 51-68 (2013a)

Rolle, M., Muniruzzaman, M., Haberer, C.M., Grathwohl, P.: Coulombic effects in 
advection-dominated transport of electrolytes in porous media: Multicomponent ionic dispersion. Geochim. Cosmochim. Acta 120, 195-205 (2013b)

Rolle, M., Kitanidis, P.K.: Effects of compound-specific dilution on transient transport and solute breakthough: A pore-scale analysis. Adv. Water Resour. 71, 186-199 (2014)

Sanchez-Vila, X., Guadagnini, A., Carrera, J.: Representative hydraulic conductivities in saturated groundwater flow. Rev. Geophys. 44, 535-540 (2006)

Staufer, F.: Impact of highly permeable sediment units with inclined bedding on solute transport in aquifers. Adv. Water Resour. 30, 2194-2201 (2007)

Singh, V.P.: The use of entropy on hydrology and water resoureces. Hydrol. Process 11, 587-626 (1997)

Stroock, A.D., Dertinger, S.K.W., Ajdari, A., Mezić, I., Stone, H.A., Whitesides, G.M.: Chaotic mixer for microchannels. Science 295, 647-651 (2002)

Tartakovsky, A.M., Tartakovsky, G.D., Scheibe, T.D.: Effects of incomplete mixing on multicomponent reactive transport. Adv. Water Resour. 32, 1674-1679 (2009)

Theis, C.V.: Aquifers and models. In: Symposium on Ground-Water Hydrology, San Francisco, California, 1967. Am. Water Resour. Assoc. Proc. Ser. 4, 138-148 (1967)

Thierrin, J., Kitanidis, P.K.: Solute dilution at the Borden and Cape Cod groundwater tracer tests. Water Resour. Res. 30, 2883-2890 (1994)

Tuxen, N., Albrechtsen, H., Bjerg, P.L.: Identification of a reactive degradation zone at a landfill leachate plume fringe using high resolution sampling and incubation techniques. J. Contam. Hydrol. 85, 179-194 (2006)

Ursino, N., Gimmi, T., Flühler, H.: Combined effects of heterogeneity, anisotripy, and saturation on steady state flow and transport: A laboratory sand tank experiment. Water Resour. Res. 37, 201-208 (2001)

Ursino, N.: Modeling media with oriented structures. Transp. Porous Med. 55, 137-151 (2004)

Weiss, J.B., Provenzale, A.: Transport and mixing in geophysical flows. Springer, Berlin (2008)

Werth, C.J., Cirpka, O.A., Grathwohl, P.: Enhanced mixing and reaction through flow focusing in heterogeneous porous media. Water Resour. Res. 42, W12414 (2006)

Willingham, T.W., Werth, C.J., Valocchi, A.J.: Evaluation of the effects of porous media structure on mixing-controlled reactions using pore-scale modeling and micromodel experiments. Environ. Sci. Technol. 42, 3185-3193 (2008)

Ye, Y., Chiogna, G., Cirpka, O.A., Grathwohl, P., Rolle, M.: Enhancement of plume dilution 
in two-dimensional and three-dimensional porous media by flow focusing in high-permeability inclusions, Water Resour. Res. 51, 5582-5602 (2015a)

Ye, Y., Chiogna, G., Cirpka, O.A., Grathwohl, P., Rolle M.: Experimental evidence of helical flow in porous media. Phys. Rev. Lett. 115, 194502 (2015b)

Ye, Y., Chiogna, G., Cirpka, O.A., Grathwohl, P., Rolle M.: Experimental investigation of compound-specific dilution of solute plumes in saturated porous media: 2-D vs. 3-D flow-through systems. J. Contam. Hydrol. 172, 33-47 (2015c)

Ye, Y., Chiogna, G., Cirpka, O.A., Grathwohl, P., Rolle, M.: Experimental investigation of transverse mixing in porous media under helical flow conditions. Phys. Rev. E 94, 013113 (2016)

Zarlenga, A., Janković, I., Fiori, A.: Advective transport in heterogeneous formations: The impact of spatial anisotropy on the breakthrough curve. Trans. Porous Med. 96, 295-304 (2013)

Zarlenga, A., Fiori, A.: Advective transport through three-dimensional anisotropic formations of bimodal hydraulic conductivity. Trans. Porous Med. 107, 573-593 (2015) 